\title{
La botella de leche rodando hacia la muerte: \\ una aproximación a un símbolo cotidiano en la obra de Jorge Eduardo Eielson ${ }^{1}$
}

\author{
Pamela Medina García ${ }^{2}$ \\ Universidad Nacional Federico Villarreal \\ cinnamonpamg@gmail.com
}

\section{RESUMEN}

Proponemos que la obra de Eielson posee un discurso cotidiano, a través del análisis de un símbolo que transita por la poesía y la plástica. Identificamos la representación de la «botella de leche» y de qué manera se instala en el arte poético mayor que Eielson plantea a partir de dos conceptos claves: gueto literario y tridimensionalidad. Nuestra propuesta entiende que, así como una botella de leche, que rueda y se llena de sentidos, los objetos cotidianos transitan y afirman el innegable anudamiento al que se someten los símbolos en la obra de Eielson, entre disciplinas artísticas y géneros literarios.

\section{PALABRAS CLAVE}

Poesía peruana, Eielson, objetos cotidianos, gueto literario, tridimensionalidad.

\section{ABSTRACT}

We propose that the work of Eielson has a daily discourse, through the analysis of a symbol that passes for poetry and the arts. We identify the representation of the «milk bottle» and how it is installed in the poetic art that Eielson proposed, from two key concepts literary ghetto and three-dimensionality. Our proposal, also, means that as a milk bottle that rolls and fills senses, the daily objects cross and asseverate the undeniable knotting that symbols in

1 Esta es una aproximación que forma parte de un estudio mayor dedicado a las isotopías de los objetos cotidianos en la obra poética y plástica de Jorge Eduardo Eielson.

2 Licenciada en Literatura por la Universidad Nacional Federico Villarreal. Actualmente, es candidata a magíster en Literatura Peruana y Latinoamericana por la Universidad Nacional Mayor de San Marcos. 
the work of Eielson are part of, between artistic disciplines and literary genres.

\section{KEY WORDS}

Peruvian poetry, Eielson, daily object, literary ghetto, three-dimensionality.

\section{Hebra inicial}

Este análisis propone que la botella de leche rueda por la poética de Eielson. Así como un objeto esférico que rueda innegablemente por espacios, la obra de Eielson posee elementos en común que transitan y se anudan interdisciplinariamente, a los que identificamos como objetos cotidianos. Desde nuestra lectura, la reiteración de dichos objetos en la urdimbre poética y plástica de Eielson determina lo que podríamos definir como un discurso cotidiano ${ }^{3}$ que atraviesa la compleja producción del autor. Por ello, planteamos seguir el rastro a un objeto símbolo ${ }^{4}$, para determinar de qué manera ancla sus sentidos y cuál es la realidad que convoca dentro del inmenso tejido de una obra que no termina de anudarse o desanudarse.

\section{Hacia una poesía de lo cotidiano}

Con anterioridad, importantes estudios e investigaciones han dado cuenta sobre el desarrollo de medulares símbolos o arquetipos $^{5}$ vinculados dentro de una poética luminosa, ígnea, incluso escatológica ${ }^{6}$, que toma posesión en la obra de Eielson. Esto es el desentrañamiento de imágenes que acercan lo mundano o terrenal con lo elevado, donde el «suelo se reúne con el cielo» (Canfield 2002a: 194), y que nos sitúa frente a una poética que en efecto viaja hacia la luz. Creo, sin embargo, también, en una poética con predilección por lo cotidiano, es decir, aquel conjunto de circunstancias cercanas que rodea o circunda la vida-relato a partir de un ritmo de conservación constante que intensifica lo ordinario frente a lo extraordinario ${ }^{7}$. En efecto, la poética de Eielson se hallará impregnada de

3 Nuestra propuesta del discurso cotidiano también analiza, en otros espacios de discusión, otros objetos en la obra de Eielson, como la ropa, la silla, la puerta, entre otros.

4 Entiendo por símbolo a un signo cuya presencia evoca otra realidad sugerida o representada por él, que trasciende al objeto.

5 Me refiero al artículo de Martha Canfield «Largo viaje del cuerpo hacia la luz» (Canfield 2002b).

6 Me refiero a los artículos de Helena Usandizaga, «Símbolos ígneos en la poesía de Jorge Eduardo Eielson» (Usandizaga 202b), y de Luis Fernando Chueca, «El discurso escatológico sobre el cuerpo en la poesía de J. E. Eielson» (Chueca 2002).

$7 \mathrm{Mi}$ concepto de lo cotidiano es una síntesis a partir de los planteamientos de la filósofa Nieves Febrer y el semiota Herman Parret. 
circunstancias cercanas que construyen a sus figuras entre la vida-relato del día a día, ya sea entre las miserias, banalidades y mediocridades en las que se encuentran sumidos los personajes, en algunos casos urbanos.

Reinos (1944) forma parte de las primeras incursiones en poesía de Jorge Eduardo Eielson. Las fuentes que alimentan esta unidad tienen un aliento natural y nocturno, de raigambre romántico, con una presencia progresiva de la muerte. Esta atmósfera se confunde con símbolos que conectan «lo elevado y lo cotidiano» (Rebaza 2004: 14). Este último resquicio se observa con claridad en un poema significativamente denominado «Poesía», que consideramos ya se revela como un arte poética que refrenda muy bien lo que hemos denominado como el discurso cotidiano:

En mi mesa muerta, candelabros

De oro, platos vacíos, poesía

De mis dientes en ruina, poesía

De la fruta rosada y el vaso

De nadie en la alfombra. Poesía

De mi hermana difunta, amarilla,

Pintada y vacía en su silla;

Poesía del gato sin vida, el reloj

Y el ladrón en el polvo. Poesía

Del viento y la luna que pasa,

Del árbol frondoso o desnudo

Que un fósforo cruza. Poesía

Del polvo en mi mesa de gala,

Orlada de coles, antigua y triste

Cristalería, dedos y tenedores (Eielson 1976: 75).

En el ritmo del poema la significación de la esencia poética parte desde una conciencia de la finitud, es decir, siguiendo a Helena Usandizaga, la poesía no es celebración sino ausencia, separación, elegía (Usandizaga 2000: 87) inspirada por la constante presencia de la muerte, a la que aludimos como un eje importante en Reinos. La clara conciencia del término o fin deriva en una necesidad de la ausencia como impulso poético que es a su vez renovación. En esta doble pulsión la «poesía» alterna su edificación sobre lo difunto («mesa muerta», «hermana difunta», "gato sin vida») que se entrelaza y da paso a los elementos de uso cotidiano (platos vacíos, silla, reloj, mesa, cristalería o tenedores). Al ser consciente de la muerte, la morada poética se instala y se aprehende progresivamente de los objetos como una posibilidad que renueva y construye el artificio poético desde lo cercano. Sin embargo, este ritmo aún es tensivo, porque el enunciador no se desprende completamente del «viento y la luna que pasa», es 
decir, de la «inspiración» natural romántica. La «poesía» reiterará su carácter destructivo en la imagen evanescente de un árbol frondoso que un fósforo cruza, lo metapoético revela así la voluntad pirómana de la poesía como un deseo de purificación y renovación intermitente. Reinos debe entenderse, con esta pieza, como el poemario que incita brevemente a la retórica de lo cotidiano, que más adelante estallará luminosamente en Habitación en Roma (1952-1954).

En otra pieza que compone Reinos, los objetos generan un ambiente hogareño y cotidiano que alude a la espesura familiar. «Poesía de la casa entre los pinos», por ejemplo, es la representación de una casa que ante el paso del tiempo solo está habitada por objetos que evocan la plenitud de una familia ausente. El visitante tardío, que experimenta la soledad de los cuerpos, estrecha contacto y lazos con los objetos y la habitación como fuente que le permite acercarse a la historia que ha quedado impregnada en ellos. Paulatinamente, el visitante afrontará el ingreso de la naturaleza que ahora habita la casa para lentamente empezar a derruirla. Con la desintegración de los objetos, todo recuerdo familiar se irá extinguiendo. El tránsito disfórico que envuelve el poema es sintetizado con un símil del trayecto de una botella de leche que rueda hacia la muerte.

Identificamos cuatro momentos en el poema: el primero corresponde a la delimitación de la muerte y ausencia familiar y las formas en las que esta es percibida a través de la atmósfera de la habitación y los objetos; el segundo momento es la identificación de la presencia tardía del visitante $y$, por tanto, su alejamiento temporal de la familia y su proximidad a la ausencia, así como también es el momento en el que la naturaleza va tomando posesión de la casa; en el tercer momento, el carácter evanescente de la muerte alerta al enunciador; finalmente, en el cuarto momento, el ingreso de la naturaleza desborda la casa para marcar la desaparición lenta de los objetos y extinguir el recuerdo; así, este proceso es un trayecto hacia la muerte al que el enunciador-visitante se somete en el mismo imperio natural. El primer momento señala lo siguiente:

Habitaciones dolientes de esta casa mía entre los pinos

Cuyas puertas se abren con sed a las estrellas

Hay en ellas una madre y una esposa suave

Cuya permanencia en el polvo es como un viejo

Plato de frijoles, una nube o una fruta antigua.

Oscuras personas, tíos, parientes que duermen

Para siempre, vigilan en la noche con su chispa azul

En el semblante. A su acera humilde (Eielson 1976: 62) 
La primera imagen que se evoca en la habitación es la maternidad (madre y esposa), como una presencia se ha quedado estática en el polvo. Intensificando este detenimiento y la cualidad materna, dadora de vida, el alimento («plato de frijoles») comparte su antigüedad. El polvo se convierte en un elemento que acentúa el paso del tiempo, de la misma forma que su carácter residual, desintegración de lo que antes fue sólido, es una huella que se impregna en todos lados, haciendo ineludible la presencia femenina. El siguiente grupo familiar que aparece, tíos y parientes, tiene una proximidad con la muerte, duermen un sueño eterno («duermen / para siempre»), a través de la noche que señala metafóricamente la culminación del ciclo vital-diurno. La reiteración de la ausencia que remarca el enunciador reviste a las habitaciones de aflicción; estas se encuentran «dolientes» porque la familia y lo cotidiano son una experiencia irrepetible. Siguiendo al crítico Camilo Fernández Cozman (1996: 136) en su análisis a la poesía de Eielson, las experiencias irrepetibles son únicas porque vinculan al individuo con la historia ${ }^{8}$. En esta casa, habitada por ausencias, la atmósfera emocional en la que se sume el enunciador revela la imposibilidad de su historia, porque la familia no regresa, salvo a través del recuerdo que la misma atmósfera mantiene gracias a la integridad de la casa, que, a diferencia de los parientes, todavía existe. En el segundo momento, el enunciador se halla temporalmente distante de la familia y apercibe el ineludible ingreso de la casa en el paisaje natural:

A sus umbríos muebles, que una ola de nieve ha deslumbrado,

Cuán tarde he de llegar hoy día,

Cuán tarde he de morir, con mi vestido augusto,

Cuando ella ya esté hundida y sus palomas

De pobreza hayan volado hacia una negra calle.

Muerto entre pinos, veré nacer el sol debajo de ella.

Corrientes de yedra ¿es este vuestro río agonizante,

Como un caballo frío, ávido de albergue, antes mis pies.

Y es esta casa mía sin cocina, con su luna plebe, la elegida? (Eielson 1976: 62)

El innegable paso del tiempo hace que la naturaleza se posesione de la casa familiar; el nexo indiscutible con su enunciador lo obliga a verse muerto debajo de ella o desear también que la naturaleza lo penetre o

8 Aunque el análisis de Fernández Cozman se concentre en Habitación en Roma, consideramos su acercamiento pertinente y válido hacia otros poemarios en la medida en que son isotopías de sentido las que se encuentran dentro del corpus seleccionado. 
se posesione de él; su casa, sin cocina y con luna innoble, es finalmente la elegida. El tercer momento del poema trae consigo la aparición del «Señor de las cenizas» que personifica el carácter evanescente de la muerte, tensión medular en el universo de Reinos, para acabar con la casa a la que el enunciador se aferra:

Señor de las cenizas ¿eres tú el que golpea desvelado?

¿No sabes también que esta casa hizo suyos el establo,

El jardín y los astros lejanos? Entablados astros,

Muros, techos fantasmas de los que dormidas aves

Penden dulcemente, sin memoria, como restos

De una antigua caza (Eielson 1976: 62-63).

En una puerta «con sed de estrellas», la casa se abre para ser habitada ahora por la naturaleza. En esta movilidad, la casa se apropia de los elementos externos y los aferra como un «astro entablado» o convierte su techo en el cielo de aves que penden como decoración.

En el cuarto momento, la intimidad es derruida por la naturaleza que ya tomó posesión del hogar, los objetos que la constituyen son dañados por un ímpetu irrefrenable:

$\mathrm{Y}$ rotas chimeneas, caños

Abiertos en la noche, tapicería hundiéndose al igual

Que un buque de cuero en un océano tibio,

Tienen en esta inmensa casa de tablas el rumor

De una botella de leche rodando sin cesar hacia la muerte.

Yo he venido tan solo a conocer sus desolados muros

Y a morir en ellos, sin sombrero y dorado como el día (Eielson 1976: 63).

La naturaleza va deteriorando los elementos necesarios para la construcción de la casa; los objetos y la atmósfera formaban parte del entramado que hacía posible la evocación de lo cotidiano y familiar. Frente al paso ineludible del tiempo, acrecentado por la erosión natural, el enunciador es consciente del fin al que identificará y familiarizará, haciendo menos trágico la muerte como verdad innegable y «doliente», con una botella de leche que rueda hacia la muerte. Este objeto concentra en su materialidad la idea del nacimiento y vida: es la leche la que provee de alimento al comienzo de la existencia. Se asume su carácter material al encontrarse como contenido en un objeto cotidiano. La botella de leche se convierte así en el símbolo cotidiano de la vida, que en el poema se dirige hacia la muerte. La casa deshabitada se convierte en una pulsión para el enunciador que a partir del impulso cotidiano entiende el trayecto de la 
vida en un objeto, porque sin objeto y sin casa es imposible recuperar la historia. Las huellas mínimas que vivificaban a la familia en la casa se van extinguiendo como parte de un ciclo vital que la naturaleza ha desbordado sobre el objeto material; este ciclo es el mismo trayecto que marca con su ruedo la botella de leche, como si la llegada de la muerte fuese después a rodar toda la vida. Así, el ruido de la botella anuncia la prontitud del final a la que el enunciador se afirma como al muro que soporta la ausencia. Deseoso ahora de homologarse con la naturaleza, el enunciador de «Poesía de la casa entre los pinos» fenecerá como el brillo del día «sin sombrero», despojado de prendas.

Al no ser un hecho pasajero, la muerte en Reinos se percibe desde distintas vertientes, y su cotidianización en la botella de leche es una de ellas. Producciones después, el mismo objeto cotidiano se reitera en un poema (o prosa poética) de largo aliento denominado Primera muerte de María $(1949)^{9}$. La pieza relata una historia de vida protagonizada por María, un personaje mundano y celestial que habita en la espesura de un barrio pobre al que se siente atada. María es descrita por su esposo a partir de su especificidad física y enclenque:

A pesar de sus cabellos opacos, de su misteriosa

delgadez,

de su tristeza áurea y definitiva como la mía,

yo adoraba a mi esposa,

alta y silenciosa como una columna de humo (Eielson 1976: 141).

El cuerpo frágil de María y su estado emocional posee un brillo quebradizo que seduce áureamente a su esposo. Con esa misma intensidad, María purifica su barrio que deslumbra en medio de una atmósfera escatológica, pero luminosa: «cubierto de deslumbrantes y altísimos planetas, / atravesado de silbidos, de extrañas pestilencias / y de perros hambrientos. / Humedecidos por las lágrimas de María... María besaba los muros de las callejuelas» (Eielson 1976: 141). El personaje se adhiere en condición y frugalidad corporal con su pequeña patria, ambos se funden en igualdad de humildad cotidiana. No solo enunciativamente, María es sagrada porque en su hábitat escatológica «la putrefacción emite destellos gloriosos» ${ }^{10} \mathrm{y}$ los cuerpos degradados (acaso también grotescos) o antiestéticos son sacros: «María era fea, su saliva sagrada» (Eielson 1976: 141). Con anterioridad,

9 Años después aparece la novela que llevará el mismo título, Primera muerte de María (1988).

10 Dialogamos esta definición con un verso del poema de Habitación en Roma: «junto al Tíber la putrefacción emite destellos gloriosos», que también discutirá, producciones después, la luminosidad de lo escatológico. 
el crítico literario Luis Fernando Chueca estabiliza, de manera importante, el discurso escatológico en la poética de Eielson. Según Chueca, hay una dimensión sagrada en las imágenes que elabora nuestro autor y son recurrentes en Poesía escrita (Eielson 2002: 175): la saliva sagrada remite, entonces, a un lugar común. La predilección de Eielson por bautizar con secreciones y fluidos a sus personajes o a su poesía en general otorga y determina, en el corpus de nuestra historia, una cualidad cotidiana en el universo de Primera muerte de María.

Las personas que pueblan el barrio de María están atentos a su sacralidad, la fe que los envuelve busca la ascensión de la mujer; sin embargo, ella es tierra y materia ajena a los cielos: «los zapatos rotos de María, como dos clavos / milenarios, / continuaban fijos en el suelo» (Eielson 1976: 141). La misma cualidad cotidiana y mundana de María niega su elevación, los zapatos rotos no son objetos que únicamente coronan la pobreza de la mujer, sino se convierten en el anclaje cotidiano y sobre todo diario (desgastado por el tiempo) que hace imposible su despegar de los suelos. Asimismo, su calzado representa adhesión a la tierra, pero más aún la imposibilidad de separarse de su barrio. Ante esto, la muchedumbre escupe la casa, la melancolía y la pobreza de María, en donde la saliva no purifica, sino menosprecia y degrada el cuerpo. En este contexto, aparece el esposo: «Hasta que aparecí yo como un caballo sediento y / me apoderé de sus senos» (Eielson 1976: 142). A diferencia de María enclenque, el esposo es un caballo ${ }^{11}$ vehemente que se apodera del cuerpo de la mujer, en específico de los senos para saciar su sed. En este punto, la botella de leche rueda del poema anterior: «La virgen espantada derramó su botella de leche / y un río de perlas sucedió a su tristeza» (Eielson 1976: 142). Con la presencia del esposo, el cuerpo, vivificado de espanto, de María desborda después de la congoja. Sus senos son botellas de leche que se derraman para calmar a su futuro esposo, como el ímpetu entre madre e hijo hambriento. Este hecho antecede a la unión marital entre los dos: «María se convirtió en mi esposa» (Eielson 1976: 142); en este sentido, la botella de leche es el seno que se descubre durante una sesión amatoria, como una parte del cuerpo femenino que le pertenece al amante, pero que, en el poema aún, llena de vida y calma de sed. La botella de leche reitera la función vital.

En el siguiente pasaje del poema, el esposo relata la llegada de otro cuerpo: «Esposo mío —-me dijo—, un hijo de tu cuerpo / devora mi cuerpo. / Te ruego, señor mío, devuélveme mi perfume, mi / botella de leche,

11 Es constante en producciones después la imagen de fortaleza viril que la representación del caballo evidencia en la poética de Eielson; por ejemplo, el poema de Habitación en Roma «poema para leer de pie en el autobús entre la puerta Flaminia y el Tritone». 
mi barrio miserable» (Eielson 1976: 142). Los esposos han concebido a su hijo y María pide de regreso cualidades que no son solo vitales para otro ser, sino vitales para ella misma; la botella de leche es tan necesaria como su perfume y su barrio miserable. El seno alimentador y dador de vida deviene en un objeto cotidiano transportable que se convirtió antes en regalo para el esposo y ahora se transforma en una ofrenda de alimento, perfume y todo lo que ella misma es para el nuevo ser que la devora. El esposo, cómplice de este ofrecimiento de vida, le retorna la botella y le da unos «sorbos redentores» a su hijo; abre la venta para devolver el «perfume adorado» y el «barrio polvoriento». Mientras la botella de leche de María alimenta a su criatura, la pequeña patria escatológica es transmitida. Este es un ritual de vida y muerte, el ser que abre los ojos se los cierra a su madre cegándola como «un planeta de oro: la felicidad» (Eielson 1976: 142). La siguiente imagen de la mujer es la de un hato de cabellos negros que ha dejado el barrio oscuro y no responde a los ruegos de su esposo. Con la desaparición del cuerpo de María, la botella de leche se reitera como un objeto transportable que en esta instancia rememora la vida: «La botella de leche yacía solitaria en una esquina, / como un cono de luz divina» (Eielson 1976: 143). La botella, que ya no rueda, es un objeto luminoso que está detenido como la huella de una vida que ha sido suspendida. Tras la muerte de María, el objeto es un elemento constante que, a pesar de la soledad y la ausencia del cuerpo, aún permanece dispuesto a dotar de vida con la «luz divina» que su misma condición física forma. El poema finaliza con los intentos del esposo por reemplazar el calor corporal de María para abrigar a su hijo.

Años más tarde, Eielson escribirá Sin título (1994-1998). La obra está conformada por poemas breves que gozan de una profusión de imágenes cotidianas; a su vez, el nexo con las artes plásticas se convierte en un eco que, desde la portada, resuena a lo largo de toda la producción ${ }^{12}$ en busca de lo visual, pero también de lo sonoro. El poema que ilustra esta cualidad es el dedicado a la botella de leche:

Una botella de leche es una botella

De leche y aunque la leche

De niño no es la misma

Que de viejo la botella de leche

Es la misma. No hay botella

Que no sea de leche ni leche

12 Susana Reisz dirá que esta obra busca observador a la vez que es lector. Ver Reisz 2002: 415-419. 
Que no sea en botella. O no hay botella

Pero tampoco hay leche

O solamente hay botella y la leche

No es de niño ni de viejo

Sino de una muchacha cuyo seno

Es una botella de leche

Que se toma solo de noche

Y en el lecho (Eielson 2004: 283)

Los primeros versos ${ }^{13}$ del poema emplean iteraciones para afirmar al objeto cotidiano y reiterar su existencia: una botella de leche, enunciada, es una botella de leche que existe. En la doble enunciación, la intención del lenguaje pretende no dejar nada al margen, sino limitar o cercar su propia significación y también formar una visualización del objeto mismo. A favor, también, de una interpretación cotidiana, la botella de leche es simplemente una botella de leche, es decir, un objeto común que pertenece a lo ordinario en contraposición a lo extraordinario. El curso del poema establece, a partir de una contraposición temporal entre niño y viejo, la existencia de la botella como objeto inmutable, salvo el contenido que sí experimenta variación. Para el enunciador, el contenido de la botella nunca es el mismo porque la necesidad de leche entre niño y viejo tampoco son las mismas. Dicha distinción reflexiona, por cierto, sobre un pasaje anteriormente producido en la obra de Eielson: María pide de regreso la botella de leche a su esposo para alimentar a su hijo. La leche de María alimentó a su hijo, pero, tras su muerte, la botella aún estaba ahí, sola en una esquina. De la misma manera se encuentra la botella que el enunciador de este poema alude: a pesar del cuerpo, la botella permanece.

El siguiente verso señala la voluntad del enunciador por anclar la botella a la leche, como una necesidad de ambos elementos por hacerse un objeto: el contenedor no puede pensarse sin contenido, es decir, la botella existe porque existe la leche y la leche, porque está dentro de la botella. Desde este verso, la poética de Eielson tiene una botella, no vacua, sino contenida como vida aprehendida dentro de un objeto que rueda por todas las piezas que conforman su gran obra. La identidad de la leche puede variar, pero el objeto que lo traslada a lo largo del tiempo siempre es el mismo: la botella es necesaria para movilizar en cualquier momento a la leche. Posteriormente, el ritmo del poema es un juego de identidades que

13 Luego de consultar dos ediciones de este poemario, el título es asumido como parte de los versos iniciales del poema. 
deshace al objeto para anclar la pertenencia de la leche. El enunciador homologa el seno de una muchacha con la botella de leche en una esfera amatoria nocturna, atribuyéndole a esta una funcionalidad que trae de regreso a la madre: el amante-hijo bebe de su leche mientras se acuesta con la madre. Al juego de personajes femeninos, la homologación también es favorecida por un artificio lúdico en el que ahora son los sonidos los que se emparentan. Las aliteraciones muchacha, leche, noche y lecho se ofrecen como un «canto melódico» (Tarazona, 2004: 19) que le entrega a esta pieza otro tipo de sensorialidad a parte de la visual. Siguiendo a Emilio Tarazona, este sería un ejemplo de la recuperación de la resonancia fónica de la palabra que emprende Eielson en su propia poética, como el poema «Nocturno» de Tema y variaciones (1950).

\section{La urdimbre plástica}

Paralelamente al ejercicio poético, la obra literaria de Eielson se anuda a su obra plástica. Una botella de leche aparece tempranamente en Reinos y cruza disciplinas a razón de un apetito creativo, para situarse en instalaciones citadinas ${ }^{14}$. Esta actitud afirma una reflexión de Eielson: «Las palabras pasan [...] la poesía permanece» (Eielson 2002a: 437), es decir, la poesía y las imágenes que se gestan en ella perseveran a pesar del género o la disciplina. En la poética del autor, los géneros se anudan a través de la reiteración de sus símbolos, resemantizando así la consigna anterior hacia «las palabras pasan, los objetos permanecen». Esta actitud surge como una preocupación por el acto creador frente a la tecnología y la postura que debe asumir la literatura, sobre todo, frente al mercado. La defensa de la palabra (Eielson 2002b) se logra, según el autor, con el abandono del gueto literario para asumir un nuevo rol que se encuentre en sintonía con paradigmas operantes en el campo filosófico, científico, artístico, religioso, político y económico.

La apertura del ghetto literario, según manifiesta el autor, coloca a la palabra en una nueva perspectiva, una tercera dimensión «en estrecho diálogo con las demás disciplinas, todas las cuales, para bien o para mal, están cambiando nuestra existencia» (Eielson 2002b: 439-440). Esta no es la de un diálogo que alimenta relaciones prolíficas entre las disciplinas; quebrar una dimensión, y abrir sus márgenes hacia lo demás, se convierte en un ejercicio que pone a prueba su propia matriz originaria en una búsqueda constante por articularla de forma regenerativa y creativa, pero, sobre todo, para criticarla. «Tridimensionalizar» es la necesidad del diálogo para

14 Nos referimos a las dos composiciones fotográficas, fechadas en 1974, denominadas Botella de leche. 
señalar los límites del marginal y opresivo gueto, pero también para sobrevivir al escenario avasallador y apocalíptico en el que, de acuerdo con Eielson, la «palabra creativa tiende a desaparecer» (Eielson 2002b: 439). Con la tridimensionalidad, Eielson concibe la creación como un ejercicio de cuestionamiento y revitalización alentado por un espíritu interdisciplinario, que tiene en la literatura su centro de origen; así, la poesía se convierte en un campo privilegiado de dicho ejercicio. No es gratuito, entonces, que los símbolos gestados en la literatura se hayan desprendido de la dimensión escrita en una dinámica de sobrevivencia hacia las artes plásticas, sobre todo, porque, como se ha evidenciado, los bordes se fueron disolviendo hacía una poesía que en Sin título, por ejemplo, explora la dimensión plástica de la escritura ${ }^{15}$.

La botella de leche es una instalación-ensamblaje que gráfica muy bien la exploración artística emprendida por Eielson en Europa a finales de la década de 1940. La relación del autor con el inicio y la efervescencia de los movimientos europeos sienta las bases para la producción plástica del artista de ahora en adelante. Para Edward Lucie-Smith, esta es la época en la que el entusiasmo por la obra de Duchamp recobra resonancia durante toda la segunda mitad del siglo XX. La inspiración de raigambre duchampiana delinea el lienzo que el movimiento francés Nouveau Réalisme (nuevo realismo) emprende a finales de la década de 1950 e inicios de la de 1960. Siguiendo a Emilio Tarazona, a diferencia de Duchamp, el movimiento descubre que la realidad presentada así ahora va a formar parte del fragmento de una «ficción monumental»: «el objeto encontrado, dejado intencionalmente al azar, resuma una serie de narraciones en la relación que se auspicia entre sus elementos. La sola presencia de estos en el contexto del arte los hace portadores de un carácter alegórico» (Tarazona 2004: 45). Este movimiento sería, entonces, la exaltación culminante del proceso de incorporación artística de toda materia preexistente, es decir, el ingreso y uso de los objetos en las dimensiones plásticas para ser los emisores de diversas ideas o sentidos. Es este movimiento el que más se emparenta con estas prácticas cotidianas en el arte de Eielson.

En 1974, Eielson manipula y coloca botellas de leche en la vía pública y en la vía privada. En una de ellas, la botella es inclinada en forma horizontal, como si estuviese rodando por el pasaje urbano en donde ha sido colocada. Es importante destacar, a pesar de que la foto no capte el

15 Para Noé Jitrik, entender una dimensión plástica en la escritura es no reducir el análisis de un poema únicamente al contenido, donde el estudioso se contenta con entender la anécdota, sino optar por otras formas de interpretación que conciban a la poesía como una obra artística (Jitrik 2001). 
movimiento de la botella, que el desplazamiento de esta afirma su carácter circular. Contrariamente, al estar en forma vertical, de pie, se destaca su carácter lineal. La otra toma nos ubica en un espacio distinto; el inodoro trae consigo la configuración del espacio privado, y aquí la botella aparece colocada sobre este de forma vertical. Si la botella de leche es el símbolo cotidiano de la vida, el inodoro, el depósito de lo escatológico, aquella materia de desecho, es el símbolo cotidiano que encierra la muerte, la despedida que es eliminada por el cuerpo. Muerte y vida comparten el mismo lugar dentro de ese espacio como hechos concluyentes que forman parte de lo cotidiano y coexisten dentro de una habitación. Así parece leer también Luis Fernando Chueca, cuando concluye que en Noche oscura del cuerpo (1955) la defecación es concebida como un sello de reconciliación con el mundo y el regreso simbólico al mundo de la infancia; ambas evocaciones se encierran en un anillo en el que el retorno de las heces a la tierra proclama la unión del hombre con el cosmos. Pese a esta circularidad recusada, consideramos que la botella y el inodoro inciden sin remordimientos en el carácter cotidiano, cercano e ineludible de la vida y la muerte: ambas coexisten en un mismo lugar. Es decir, el de señalar en objetos cargados de sentidos el tránsito de la vida hacia la muerte, que se gesta en la poesía para acabar en la misma habitación-fotografía del arte.

\section{El anudamiento}

Una botella de leche, en la práctica poética, es un símbolo claro de la conciencia cercana de vida y muerte que paulatinamente incrementa su significación a lo largo de la producción de Eielson. Es el contenedor de significaciones cuyo contenido alimenta con «sorbos redentores» el apetito agónico de una obra que está en búsqueda de hidratación constante para no morir. La necesidad de rodar se convierte, entonces, en una condición medular de la notificación ante la finitud: la apetencia que impulsa el trayecto de sus símbolos por encima de los márgenes literarios hacia los artísticos. Es la poesía tridimensional que también en el arte de los objetos ha encontrado una morada. En este sentido, las hebras del inmenso tejido están teñidas de un códice cotidiano que, frente a la iteración de una imagen, alerta una obra que no termina de anudarse o desanudarse. 


\section{REFERENCIAS BIBLIOGRÁFICAS}

\section{Primaria}

EIELSON, Jorge (1974). Botella de leche.

(1998). Poesía escrita. Bogotá: Grupo Editorial Norma.

(2002a). «Para una preparación poética». En José Ignacio Padilla (editor). Nudo. Lima: Fondo Editorial de la Pontificia Universidad Católica del Perú.

(2002b). «Defensa de la palabra: a propósito de “El diálogo infinito"». En José Ignacio Padilla (editor). Nudo. Lima: Fondo Editorial de la Pontificia Universidad Católica del Perú.

\section{Secundaria}

CANFIELD, Martha (2002a). Jorge Eduardo Eielson. Nudos y asedios críticos. Madrid: Editorial Iberoamericana.

(2002b). «Largo viaje del cuerpo hacia la luz». En José Ignacio Padilla (editor). Nudo. Lima: Fondo Editorial de la Pontificia Universidad Católica del Perú.

CHUECA, Luis Fernando (2002). El discurso escatológico sobre el cuerpo en la poesía de J. E. Eielson». En José Ignacio Padilla (editor). Nudo. Lima: Fondo Editorial de la Pontificia Universidad Católica del Perú.

FERNÁNDEZ COZMAN, Camilo (1996). Las huellas del aura. Lima: Latinoamericana Editores.

REBAZA, Luis (2004). «Una escalera sostenida sobre la arena: la construcción poética escrita y no-escrita de Jorge Eduardo Eielson». En Arte poética. Lima: Fondo Editorial de la Pontificia Universidad Católica del Perú.

REISZ, Susana (2002). «Eielson visionario». En José Ignacio Padilla (editor). Nudo. Lima: Fondo Editorial de la Pontificia Universidad Católica del Perú.

TARAZONA, Emilio (2004). La poética visual de Jorge Eielson. Lima: Ed.á.

USANDIZAGA, Helena (2002b). «Símbolos ígneos en la poesía de Jorge Eduardo Eielson. En Martha Canfield (editora). Jorge Eduardo Eielson. Nudos y asedios críticos. Madrid: Editorial Iberoamericana.

\section{Complementaria}

ESTÉBANEZ, Demetrio (2004). Diccionario de términos literarios. Madrid: Alianza Editorial. 
FEBRER, Nieves (2008). Lo cotidiano: entorno y artificio. Formas de representación en el arte contemporáneo: cine, fotografía, videoarte y literatura (1970-2003). Tesis para obtener el grado de doctora en Filosofía y Letras. Universidad de Valladolid.

FRIEDRICH, Hugo (1959). Estructura de la lírica moderna. Barcelona: Seix Barral.

JITRIK, Noé (2001). «La figura que reside en el poema». En La dimensión plástica de la escritura. México D. F.: Benemérita Universidad Autónoma de Puebla.

LUCIE-SMITH, Edward (1983). El arte hoy. Del expresionismo abstracto al nuevo realismo. Madrid: Cátedra.

PARRET, Herman (1995). «Vivir el tiempo». En De la semiótica a la estética enunciación, sensación, pasiones. Buenos Aires: Edicial. 